\title{
The Modeling of Expectations in Empirical DSGE Models: a Survey
}

\author{
FABIO MILANI* \\ University of California, Irvine
}

June 30, 2012

\begin{abstract}
This paper surveys the treatment of expectations in estimated Dynamic Stochastic General Equilibrium (DSGE) macroeconomic models.

A recent notable development in the empirical macroeconomics literature has been the rapid growth of papers that build structural models, which include a number of frictions and shocks, and which are confronted with the data using sophisticated full-information econometric approaches, often using Bayesian methods.

A widespread assumption in these estimated models, as in most of the macroeconomic literature in general, is that economic agents' expectations are formed according to the Rational Expectations Hypothesis (REH). Various alternative ways to model the formation of expectations have, however, emerged: some are simple refinements that maintain the REH, but change the information structure along different dimensions, while others imply more significant departures from rational expectations.

I review here the modeling of the expectation formation process and discuss related econometric issues in current structural macroeconomic models. The discussion includes benchmark models assuming rational expectations, extensions based on allowing for sunspots, news, sticky information, as well as models that abandon the REH to use learning, heuristics, or subjective expectations.
\end{abstract}

Keywords: Expectations Formation, DSGE Models, Rational Expectations, Adaptive Learning, Survey Expectations, New Bayesian Macroeconometrics.

JEL classification: C52, D84, E32, E50, E60.

* I would like to thank the editors of this journal Tom Fomby, Carter Hill, and Ivan Jeliazkov, for giving me the opportunity of writing this survey, and an anonymous referee for comments. Address for Correspondence: Fabio Milani, Department of Economics, 3151 Social Science Plaza, University of California, Irvine, CA 92697-5100. Phone: 949-824-4519. Fax: 949-824-2182. E-mail: fmilani@uci.edu. Homepage: http://www.socsci.uci.edu/ ${ }^{f m i l a n i . ~}$ 


\section{Introduction}

How expectations are formed is a central issue in economics. Consumers, for example, need to form expectations about future income, taxes, interest rates, inflation, when taking their consumption and saving decisions, firms need to form expectations about future relative and aggregate prices, future demand conditions and sales, future marginal costs, and so forth, when deciding the current prices of their products and current levels of investment to maximize expected discounted profits, and policymakers need to forecast future inflation and output to set policies and maximize societal welfare. Most other economic decisions are affected in similar ways by expectations about the future.

The importance of expectations for individual decisions translates into a key role of the state of aggregate expectations for outcomes at the macroeconomic level as well. The dynamics of the main variables of interest to macroeconomists, such as output, aggregate consumption, investment, inflation, wages, stock prices, and so forth, depend on expected future values of the same aggregate variables and of other related variables.

Economists have long recognized the special role of expectations and attempted to formally model the expectations formation process. In the earlier stages of economic modeling, expectations were often assumed to be formed in a naïve or static fashion, as simply equal to the past values of the variables to be forecasted (e.g., Marshall, 1890, and Kaldor, 1938, in the cobweb model). Subsequent research introduced "adaptive expectations" (first in Fisher, 1911, 1930, then in the seminal works by Cagan, 1956, and Friedman, 1957): expectations depend on previous period's expectations plus an error-correction term, and they can be equivalently written as a distributed lag of past observations, with exponentially-declining weights.

Since the work of Lucas (1976) and Sargent and Wallace (1975), however, which expanded on earlier work by Muth (1961), the dominant assumption in macroeconomics and a true building block of macroeconomic theory has been the Rational Expectations Hypothesis (REH). Rational agents in the model form expectations that correspond to the same mathematical conditional expectation implied by the model that the researcher is using. Therefore, expectations are model-consistent: agents in the model form expectations that happen to correspond to the true expectations generated by the model itself. In the most typical applications, economic agents are assumed to know the form and solution of the model, they know the parameters describing preferences, technology, constraints, and policy behavior, they know the distributions of exogenous shocks and the relevant parameters describing those distributions. The only source of uncertainty for agents is given by the realizations of the random exogenous shocks, which are unforecastable in advance (agents, instead, have access 
to the full history of the shocks).

Since Lucas, Sargent, and Wallace's so-called rational expectations revolution, macroeconomic models have almost universally employed the rational expectations assumption.

The quantitative properties of these models have been for a long time evaluated using calibration to match a number of moments and stylized business cycle facts (e.g., Kydland and Prescott, 1982). More empirically-oriented work, using techniques more rooted in statistical theory, instead, often reverted to models that imposed only a limited amount of restrictions compared to rational expectations models with stringent cross-equation restrictions (e.g., VAR studies), or entirely backward-looking non-microfounded models in which expectations did not play direct roles (e.g., Rudebusch and Svensson, 1999), but which were able to fit macroeconomic time series well.

A technique that revealed useful to estimate equations exploiting the rational expectations hypothesis was GMM. Hansen (1982) and Hansen and Singleton (1982) show how GMM allows the estimation of nonlinear RE models, using moment conditions derived from the model's Euler equations. Several influential papers use GMM to estimate single equations describing the optimality condition for consumption (e.g., Hall, 1978, Hansen and Singleton, 1983), the evolution of inflation (Gali' and Gertler, 1999), or the evolution of U.S. monetary policy over the post-war period (Clarida, Gali', and Gertler, 2000). These limited-information estimation approaches exploit only a subset of the restrictions and structure imposed by the REH.

Only more recently, however, the estimation of fully structural models under rational expectations has become common and the relative literature has flourished. The models are usually estimated using full-information methods rather than equation by equation, the rational expectations cross-equation restrictions are thus exploited to full extent, and the estimation is likelihood-based. Various papers estimate the models using classical approaches and maximum likelihood estimation (e.g., Ireland, 2004), but the majority of the empirical literature focused on the estimation of structural models now adopts a Bayesian perspective and it exploits MCMC techniques (e.g., Fernandez-Villaverde, Guerron, and Rubio-Ramirez, 2010, and Del Negro and Schorfheide, 2011, provide recent reviews).

In this survey, I will review the modeling of the expectations formation process in the latter generation of microfounded macroeconomic models that are taken to the data using full-information methods. I will start with the dominant approach in the literature based on the REH. I will then review the refinements related to the modeling of expectations that have been introduced in the literature, and which conserve the benchmark assumption of rational expectations. The survey then moves on to consider the literatures that deviate from the REH. The deviation may be 'small', as 
under a large part of the adaptive learning literature, or more drastic (for example, by assuming heuristics).

Moreover, a new direction that seems to have become more frequent in the recent literature is the use of direct expectations data from surveys which, although having being often used to test the rational expectations hypothesis, hadn't really been exploited in the estimation of structural general equilibrium models until recently.

The main focus of this survey is, therefore, on the conventional and alternative modeling of expectations in dynamic macroeconomic models based on a general equilibrium environment. The survey is interested in empirical work, and specifically in the empirical work that focuses on the estimation of DSGE models. Theoretical research based on alternative models of expectations is, therefore, with only few exceptions, not mentioned in the survey. Empirical research that has expectations as the main focus, but which is not based on structural DSGE models is also generally excluded from the scopes of the survey. The interests of the author, space, and time constraints in the preparation of the survey for this volume necessarily make it a selective and incomplete survey: given the breadth of the topic and the deep interest that economists have always shown toward the role of expectations, many relevant papers, literatures, modeling approaches, and so forth, had to be omitted. The readership of this journal is varied and not necessarily focused on macroeconomics. This survey is, therefore, meant to be accessible to practitioners and readers outside the empirical macroeconomic literature.

The paper is organized as follows. Section 2 presents a benchmark current-generation DSGE model, which mainly serves to highlight the role of expectations in a state-of-the-art macro setting. Section 3 turns to the discussion on how expectations are modeled and typically inserted in such DSGE models. The initial focus is on the conventional assumption of rational expectations. Section 4 discusses the estimation of rational expectations DSGE models with particular reference to the context of the New Bayesian Macroeconometrics literature. I discuss advantages and problems with the REH in section 5, and move to present refinements, which, however, still maintain the rational expectations environment, in section 6. Section 7 discusses departures from rational expectations, with emphasis on models with adaptive learning, which represent the main alternative in the literature. Section 8 presents recent developments, which exploit observed data on expectations in the estimation of models with or without rational expectations. Section 9 concludes. 


\section{A Prototypical DSGE Model}

I briefly present a benchmark DSGE model that is used in its many variations in a large part of the current empirical macroeconomic literature. The model is based on Smets and Wouters (2007), who extend the model used in Christiano, Eichenbaum, and Evans (2004), and is reported here (in its loglinearized form) mostly to show the large role that various expectations play on the dynamics of the economy: ${ }^{1}$

$$
\begin{aligned}
y_{t} & =c_{y} c_{t}+i_{y} i_{t}+u_{y} u_{t}+\varepsilon_{t}^{g} \\
c_{t} & =c_{1} c_{t-1}+\left(1-c_{1}\right) E_{t} c_{t+1}+c_{2}\left(l_{t}-E_{t} l_{t+1}\right)-c_{3}\left(r_{t}-E_{t} \pi_{t+1}+\varepsilon_{t}^{b}\right) \\
i_{t} & =i_{1} i_{t-1}+\left(1-i_{1}\right) E_{t} i_{t+1}+i_{2} q_{t}+\varepsilon_{t}^{i} \\
q_{t} & =q_{1} E_{t} q_{t+1}+\left(1-q_{1}\right) E_{t} r_{t+1}^{k}-\left(r_{t}-E_{t} \pi_{t+1}+\varepsilon_{t}^{b}\right) \\
y_{t} & =\Phi_{p}\left(\alpha k_{t}^{s}+(1-\alpha) l_{t}+\varepsilon_{t}^{a}\right) \\
k_{t}^{s} & =k_{t-1}+u_{t} \\
u_{t} & =u_{1} r_{t}^{k} \\
k_{t} & =k_{1} k_{t-1}+\left(1-k_{1}\right) i_{t}+k_{2} \varepsilon_{t}^{i} \\
\mu_{t}^{p} & =\alpha\left(k_{t}^{s}-l_{t}\right)+\varepsilon_{t}^{a}-w_{t} \\
\pi_{t} & =\pi_{1} \pi_{t-1}+\pi_{2} E_{t} \pi_{t+1}-\pi_{3} \mu_{t}^{p}+\varepsilon_{t}^{p} \\
r_{t}^{k} & =-\left(k_{t}-l_{t}\right)+w_{t} \\
\mu_{t}^{w} & =w_{t}-\left(\sigma_{l} l_{t}+\frac{1}{1-h / \gamma}\left(c_{t}-\frac{h}{\gamma} c_{t-1}\right)\right) \\
w_{t} & =w_{1} w_{t-1}+\left(1-w_{1}\right) E_{t}\left(w_{t+1}+\pi_{t+1}\right)-w_{2} \pi_{t}+w_{3} \pi_{t-1}-w_{4} \mu_{t}^{w}+\varepsilon_{t}^{w} \\
r_{t} & =\rho_{r} r_{t-1}+\left(1-\rho_{r}\right)\left[\chi_{\pi} \pi_{t}+\chi_{y}\left(y_{t}-y_{t}^{*}\right)\right]+\chi_{\Delta y}\left(\Delta y_{t}-\Delta y_{t}^{*}\right)+\varepsilon_{t}^{r} .
\end{aligned}
$$

The main building blocks on which the above model is based consist of a basic Real Business Cycle model, in which investment decisions, capital accumulation, households' labor supply decisions on how many hours to work, and shocks to total factor productivity play an important role, and of a stylized New Keynesian model, which allows for imperfect competition, nominal rigidities such as price and wage stickiness, and which assumes an interest-rate rule for monetary policy. The model is a successful combination of the two approaches, which is further extended to include features as variable capital utilization, habit formation in consumption, indexation in price and wage setting, and a variety of additional disturbances that help the model in fitting the data.

\footnotetext{
${ }^{1}$ The reader is referred to their papers for additional details on the models and full derivations from microfoundations.
} 
Equation (1) gives the economy's aggregate resource constraint. Output $y_{t}$ is absorbed by consumption $c_{t}$, by investment $i_{t}$, and by the resources used to vary the capacity utilization rate $u_{t}$. The model assumes that government spending is exogenous and captured by the disturbance $\varepsilon_{t}^{g}$.

Equation (2) represents the Euler equation for consumption, where the contemporaneous value for consumption depends on expectations about future consumption, on lagged consumption, on current and expected hours of work $l_{t}$, and on the ex-ante real interest rate $\left(r_{t}-E_{t} \pi_{t+1}\right)$. The term $\varepsilon_{t}^{b}$ indicates a risk-premium shock (an exogenous shock that affects yields on bonds), which is sometimes substituted in the literature by a preference or discount-factor shock, which enters in similar ways (although with switched sign) in the Euler equation.

Equations (3) and (4) characterize the dynamics of investment. Current investment is influenced by expectations about future investment, by lagged investment, and by the value of capital stock $q_{t}$, which is itself driven by expectations about its future one-period-ahead value, by expectations about the rental rate on capital $E_{t} r_{t+1}^{k}$, and by the ex-ante real interest rate. The disturbances $\varepsilon_{t}^{i}$ and $\varepsilon_{t}^{b}$ affect the behavior of investment. The first denotes investment-specific technological change, while the second is the same risk-premium shock that also enters the consumption Euler equation and, hence, helps in fitting the comovement of the investment and consumption series.

Equation (5) is a Cobb-Douglas production function: output is produced using capital services $k_{t}^{s}$ and labor hours. Neutral technological progress enters the expression as the exogenous shock $\varepsilon_{t}^{a}$. The coefficient $\Phi_{p}$ captures fixed costs in production. Equation (6) accounts for the possibility to vary the rate of capacity utilization: capital services are a function of the capital utilization rate $u_{t}$ and of the lagged capital stock $k_{t-1}$. The degree of capital utilization itself varies as a function of the rental rate of capital, as evidenced by equation (7). From equation (11), the rental rate of capital is a function of the capital to labor ratio and of the real wage. Capital, net of depreciation, is accumulated according to equation (8).

Equations (9), (10), (12), and (13) summarize the equilibrium in the goods and labor markets. Inflation $\pi_{t}$ is determined as a function of lagged inflation, expected inflation, and the price mark-up $\mu_{t}^{p}$, which is equal to the difference between the marginal product of labor $\left(\alpha\left(k_{t}^{s}-l_{t}\right)+\varepsilon_{t}^{a}\right)$ and the real wage $w_{t}$. The real wage depends on lagged and expected future real wages, on past, current, and expected inflation, and on the wage mark-up $\mu_{t}^{w}$, which equals the difference between the real wage and the marginal rate of substitution between consumption and leisure. Inflation and wage dynamics are also affected by the exogenous price and wage markup shocks $\varepsilon_{t}^{p}$ and $\varepsilon_{t}^{w}$ (which are obtained by assuming a time-varying elasticity of substitution among differentiated goods). 
Finally, equation (14) describes a Taylor rule: the monetary authority sets the interest rate $r_{t}$ in response to changes in inflation and the output gap, defined as the difference between actual output and the level of output that would be achieved in the same economy, but under flexible prices. The policy rate also responds to the growth in the output gap. The term $\varepsilon_{t}^{r}$ captures random deviations from the systematic policy rule.

The coefficients in the model are mostly composite functions of the 'deep' preference and technology parameters, such as the degree of habits in consumption, the elasticities of intertemporal substitution and of labor supply, the Calvo price rigidity coefficients, and so forth.

The model governs the dynamics of 14 endogenous variables. The sources of uncertainty are given by 7 random shocks: to government spending, risk-premium, investment-specific and neutral technology, price and wage markup, and monetary policy. All exogenous shocks, often with the exception of the monetary policy shock, which is usually assumed to be i.i.d., are assumed to follow $\operatorname{AR}(1)$ or $\operatorname{ARMA}(1,1)$ processes in the literature.

Seven expectation terms directly enter the model: expectations about future consumption $E_{t} c_{t+1}$, hours of work $E_{t} l_{t+1}$, inflation $E_{t} \pi_{t+1}$, investment $E_{t} i_{t+1}$, value of capital $E_{t} q_{t+1}$, rental rate of capital $E_{t} r_{t+1}^{k}$, and wages $E_{t} w_{t+1}$. The expectations are typically modeled as being formed according to the rational expectations hypothesis. The notation $E_{t}$ in the model denotes modelconsistent rational expectations, i.e., the mathematical conditional expectation based on time- $t$ information set and derived from the model (1) to (14) itself.

\section{The Modeling of Expectations}

The quasi totality of papers in the empirical macroeconomics literature that is based on structural general equilibrium models shares one assumption: that expectations by households, firms, policymakers, entrepreneurs, etc., are formed according to the rational expectations hypothesis.

The informational assumptions implicit in the REH - at least in the form in which it is typically used in estimated DSGE models - are quite strong: agents in the economy are assumed to know the values of all the parameters, the correct structural form of the model, the distribution of the shocks, their mean, autocorrelation, and standard deviation, and so forth. The only source of uncertainty for agents remains given by the future realizations of the shocks. ${ }^{2}$ It should be mentioned that

\footnotetext{
${ }^{2}$ Admittedly, I am considering here a rather strong form of the REH, which seems to be the form that is predominant in the empirical DSGE literature. A weaker form of the REH would simply posit that economic agents in the models optimally use all the available information when forming their expectations. In that case, the informational assumptions can be weakened at will, while keeping the sensible feature that agents process the information optimally. In this survey, the benchmark case of rational expectations is assumed to be the one under the strong form. Only recently, the DSGE literature has made progress in estimating empirically-realistic environments in which agents optimally use the available information, under various degrees of information limitations; some examples will
} 
rational expectation frameworks can be, and have been, extended to limit the amount of knowledge that is attributed to agents. But in those cases, the degree of rationality and capacity to process information that agents are assumed to have may even increase. If agents are assumed to lack knowledge about some of the parameters or about some of the state variables in the system, they are allowed to learn them optimally in a Bayesian fashion. Sometimes, the fully-rational learning solution gives rise to behavior that, some argue, is not entirely realistic (for example, optimal learning in an environment in which the parameters of the economy are not fully known, may imply "experimentation", meaning that it is optimal for decision makers to sometimes take stark decisions only with the scope to speed up their learning process).

Moreover, in the model presented above, but also in more stylized models, expectations of different agents - consumers, firms, and policymakers - matter. In more complicated environments, such as models that incorporate financial and credit frictions, expectations by entrepreneurs, financial intermediaries, and so forth, would also have to be considered. Under the strong form of the REH outlined above, the expectations of all the different actors are assumed to coincide. Obviously, this might not be true in reality. Mankiw, Reis, and Wolfers (2003) document substantial differences in the inflation forecasts by households and professional forecasters (which exist both within and between groups) and suggest 'disagreement', measured by the cross-sectional variation of forecasts at each point in time, as a variable that may matter to understand business cycle dynamics. Policymakers also routinely monitor the expectations of different economic actors: the Swedish Riksbank, for example, publishes in its Monetary Policy Report inflation and other forecasts by households, companies, and money market players. Nontrivial differences emerge among their forecasts as well. ${ }^{3}$

When the interest on rational expectations models started to turn to their consequences for econometric practice, it became common to estimate single equations, typically Euler equations derived from economic agents' optimization, even in nonlinear form, by GMM (e.g., Hansen and Singleton, 1982). The GMM approach allowed researchers to avoid making distributional assumptions about the error terms. Moreover, since estimations were based on a limited information approach, misspecification in parts of the economic system other than the equation being considered, was prevented from contaminating the estimates for the main parameters of interest. On the other hand, limited-information approaches are known to be inefficient compared to full-information counterparts and they refrain from exploiting all the existing cross-equation restrictions that rational expectations imply. Various works (e.g., Linde', 2005, in the case of the estimation of New

be discussed later. Many of the alternatives that will be discussed later in the survey are actually consistent with the weaker form of the REH; under adaptive learning, agents's behavior may not be fully optimal, but it is generally intended to be a good approximation of optimal behavior (e.g., Cogley and Sargent, 2008).

${ }^{3}$ Additional evidence that expectations from surveys are heterogeneous is provided in Branch (2004, 2007). 
Keynesian Phillips curves) also show that limited-information methods may lead to imprecise and biased estimates and are outperformed by full-information approaches when the equations of interest are characterized by both backward-looking and forward-looking behavior.

In recent years, system estimation by full-information methods has become predominant in the empirical macroeconomic literature. The model's equilibrium conditions are often loglinearized as in (1)-(14), although estimation approaches based on higher-order approximations or using nonlinear models are possible (the analyses are more complicated, but these cases have been considered in An and Schorfheide, 2007, and Fernandez-Villaverde and Rubio-Ramirez, 2007, for example).

Under the benchmark assumption of rational expectations, the model presented in (1)-(14), along with the processes for the shocks, or any other model of choice, can be rewritten in statespace form as:

$$
\Gamma_{0} \xi_{t}=\Gamma_{1} \xi_{t-1}+\Psi \epsilon_{t}+\Pi \eta_{t}
$$

where

$$
\begin{aligned}
\xi_{t} & =\left[\Gamma_{t}, \Xi_{t}, \varepsilon_{t}, \tilde{\Gamma}_{t-1}\right]^{\prime} \\
\Gamma_{t} & =\left[y_{t}, c_{t}, i_{t}, q_{t}, l_{t}, k_{t}^{s}, u_{t}, k_{t}, \mu_{t}^{p}, \pi_{t}, r_{t}^{k}, \mu_{t}^{w}, w_{t}, r_{t}\right]^{\prime} \\
\Xi_{t} & =\left[E_{t} c_{t+1}, E_{t} i_{t+1}, E_{t} q_{t+1}, E_{t} l_{t+1}, E_{t} \pi_{t+1}, E_{t} r_{t+1}^{k}, E_{t} w_{t+1}\right]^{\prime} \\
\varepsilon_{t} & =\left[\varepsilon_{t}^{g}, \varepsilon_{t}^{b}, \varepsilon_{t}^{i}, \varepsilon_{t}^{a}, \varepsilon_{t}^{p}, \varepsilon_{t}^{w}, \varepsilon_{t}^{r}\right]^{\prime} \\
\tilde{\Gamma}_{t} & =\left[y_{t}, c_{t}, i_{t}, w_{t}\right]^{\prime} \\
\epsilon_{t} & =\left[\epsilon_{t}^{g}, \epsilon_{t}^{b}, \epsilon_{t}^{i}, \epsilon_{t}^{a}, \epsilon_{t}^{p}, \epsilon_{t}^{w}, \epsilon_{t}^{r}\right]^{\prime} \\
\eta_{t} & =\left[\eta_{t}^{c}, \eta_{t}^{i}, \eta_{t}^{q}, \eta_{t}^{l}, \eta_{t}^{\pi}, \eta_{t}^{r k}, \eta_{t}^{w}\right]^{\prime},
\end{aligned}
$$

where $\xi_{t}$ denotes the state vector of the system, which includes the model endogenous variables collected in $\Gamma_{t}$, the expectation terms $\Xi_{t}$, the structural disturbances $\varepsilon_{t}$, and a subset of the endogenous variables in lagged terms (since these are typically needed to use growth rates of nonstationary variables in the estimation), and where $\epsilon_{t}$ includes i.i.d. innovations, and $\eta_{t}^{c}=c_{t}-E_{t-1} c_{t}$, $\eta_{t}^{i}=i_{t}-E_{t-1} i_{t}$, and so forth, denote the expectational errors, with the property that $E_{t} \eta_{t+1}=0$ for all t's. All the disturbance terms that are not i.i.d. (e.g., shocks that follow an AR(1) process, such as the the technology shock, which evolves as $\left.\varepsilon_{t}^{a}=\rho_{a} \varepsilon_{t-1}^{a}+\sigma_{a} \epsilon_{t}^{a}\right)$ are typically included in the vector $\varepsilon_{t}$ in (19) and they, are, therefore added in the state variable vector $\xi_{t}$, while the corresponding i.i.d. innovations (e.g., $\epsilon_{t}^{a}$ for the technology shock) or the shocks that are assumed as already i.i.d. in the model enter the vector $\epsilon_{t}$ in (21). 
The model can then be solved using a variety of techniques (e.g. Blanchard and Kahn, 1980, Uhlig, 1999), for example following the approach by Sims (2000).

This approach is particularly attractive since it makes clear the interpretation of the expectational errors in terms of the structural shocks. Under rational expectations, in fact, the expectational errors are obtained as a function of the structural innovations and, hence, they can be solved out of the model, as made clear in (24) below. Sims' approach imposes restrictions on the growth rate of the variables in the vector $\xi_{t}$ and it implies that a stable unique solution exists if there is a one-to-one mapping between the expectational errors and the structural shocks, which permit to remove the explosive components of $\xi_{t}$. The expectational errors are found from

$$
\Psi^{*} \epsilon_{t}+\Pi^{*} \eta_{t}=0
$$

where $\Psi^{*}$ and $\Pi^{*}$ are transformed matrices with row vectors corresponding to the unstable eigenvalues in the system. Finally, if the equilibrium exists and is unique, the approach yields the rational expectations solution:

$$
\xi_{t}=F \xi_{t-1}+G \epsilon_{t}
$$

where only the exogenous shocks $\epsilon_{t}$ remain as source of randomness in the economy; the elements in the matrices $F$ and $G$ are complicated nonlinear functions of the deep parameters in the original model.

\section{Expectations \& the "New (Bayesian) Macroeconometrics"}

The model solution in (24) can be easily taken to the data. Under the conventional assumption that the shocks are distributed as Normal, and given the linearity of the system, the RE solution can be paired to the observation equation $O B S_{t}=H_{0}+H_{1} \xi_{t}$, and the likelihood function can be straightforwardly computed using the Kalman filter. ${ }^{4}$

While the model at this point could be estimated by classical methods, such as maximum likelihood, the dominant approach in the literature is to estimate the model using a Bayesian approach. Only relatively simple models could in fact be estimated by maximum likelihood, unless informative priors (in which case, one would employ a mixed approach by maximizing the posterior probability) or tight constraints on the parameter bounds are assumed.

Hence, the most popular approach in the literature has become the use of a Bayesian approach. The estimation works by generating draws from the posterior distribution, using MCMC (Markov

\footnotetext{
${ }^{4}$ The vector $H_{0}$ typically contains steady-state parameters, while $H_{1}$ is a selection matrix relating the observable series to the corresponding variables in the structural model.
} 
chain Monte Carlo) methods, with the likelihood obtained at each draw through the Kalman filter. In the case of structural DSGE models, the MCMC procedure of choice is usually the random-walk Metropolis-Hastings algorithm.

A huge literature has appeared in the last ten years using exactly this approach. Various surveys of the literature are now available (e.g., An and Schorfheide, 2007, Del Negro and Schorfheide, 2011, Fernandez-Villaverde, Guerron, and Rubio-Ramirez, 2010). Fernandez-Villaverde et al. (2010) propose the term "New Macroeconometrics" to define this recently developed literature. Given the Bayesian focus, this could also be labeled "New Bayesian Macroeconometrics".

In spite of any label, such evolution represents a clear shift from most of the previous macroeconomics literature, since now it is common and also expected to subject theoretical models to system-based estimation and to more stringent empirical tests.

\section{Problems with the Rational Expectations Hypothesis}

The hypothesis of rational expectations carries a number of advantages. It is elegant and it leads to internally-coherent theories: by construction, expectations by agents in the model are, on average, confirmed by the outcomes of the model. It solves obvious problems faced by previous static or adaptive expectation models: under those precursors, agents in the economy would make systematic forecast errors. Systematic forecast errors are instead prevented by the rational expectations hypothesis.

From a modeling point of view, rational expectations are particularly appealing because they remove all the parameters and degrees of freedom that may otherwise characterize the equations for expectations. Under the REH, modelers cannot arbitrarily vary expectations to fit different facts, since expectations are univocally determined by the model at hand.

But rational expectations have drawbacks too. It is well known that models with rational expectations, at least in their simplest form, typically fail to match the persistence of macroeconomic variables. ${ }^{5}$ As a result, the models need to be extended to include, in addition to several highlyautocorrelated exogenous shocks, various so-called "mechanical" sources of endogenous persistence.

Many have now become ubiquitous. First, the form of the households' utility function has

\footnotetext{
${ }^{5}$ For example, the basic RBC model fails to match the serial correlation of macroeconomic variables at business cycle frequencies unless an exogenous technology shock with autocorrelation in the 0.8-0.99 range is assumed. It is well known that the model lacks strong internal propagation mechanisms and the variables largely inherit the properties of the exogenous shock. In the benchmark New Keynesian model, the lack of persistence is evident by noticing that the variables respond instantly and adjust very quickly to shocks, such as a monetary policy shock. It is worth pointing out, however, that these model failures may be due to the REH, but also to other modeling features (optimizing behavior, utility function specifications, etc.) that are unrelated to expectations. As it's often the case, it is hard to separate the respective contributions of each element.
} 
changed. Households are assumed to derive utility not only from their current and future levels of consumption, but from the deviation of consumption from a stock of habits, either driven by the consumption level of their neighbors (through "catching up" or "keeping up" with the Joneses effects, both proxied by the level of aggregate consumption in the economy, although with different timing assumptions) or corresponding to their own consumption level in the previous period. The utility function is definitely plausible, but it still remains unclear whether microeconomic data are actually supportive of the existence of habit formation in consumption or not (e.g., Dynan, 2000, uses consumption data from the Panel Study of Income Dynamics and she fails to find evidence of habit formation at the individual level).

In addition, it is now standard to assume variable capital utilization and adjustment costs of investment or capital in the real side of the model. These modifications have a long history: variable capital utilization is necessary to obtain more realistic estimates of the Solow residual; investment adjustment costs are essential to match the sluggish response of investment to shocks; without those, the model responses would be highly unrealistic.

Other assumptions that are routinely added in the models concern indexation to past inflation in price and wage-setting decisions. Indexation implies that firms that are not allowed to reoptimize their prices or wage contracts in a given period, still change them to at least reflect increases in last period's aggregate inflation rate. These admittedly ad-hoc indexation rules have been disproved many times: various studies have shown that they are inconsistent with the microeconomic evidence on price setting (e.g., Nakamura and Steinsson, 2008, Altissimo, Ehrmann, and Smets, 2006). It can certainly be argued that they are hardly structural and hence subject to the Lucas critique; nonetheless, they remain present in most macroeconomic models.

Another concern with estimated rational expectations models concerns the identification of structural parameters. Various papers (e.g., Canova and Sala, 2009, Beyer and Farmer, 2004) demonstrate that rational expectations models suffer from non-identification or weak identification of many crucial parameters. In the empirical DSGE literature, often the priors are not updated and end up overlapping with the posterior distributions for subset of parameters. It is well known that non-identification of some parameters does not create problems for the estimation of the model in a Bayesian context (Poirier, 1998). But a reading of the literature shows that this often happens for parameters as the Taylor rule response coefficients to inflation and output gap, which are key parameters for monetary business cycle models and also largely control the determinacy properties of the system equilibrium. Here, it is worth pointing out, however, that many identification problems may still remain under alternative approaches that deviate from rational expectations. 
The main problem, however, with the REH would be if the modeling of expectations was grossly misspecified, not only at the individual, but also at the aggregate level, and if the main conclusions were widely sensitive to even small deviations from the benchmark rational expectations assumption. Most tests in the literature are, in fact, implicitly joint tests of the model or theory at hand and of the associated rational expectations hypothesis. This is true for tests of the permanent income/life cycle hypothesis, tests of asset pricing equations, exchange rate models, Phillips curve specifications, and so forth. Misspecification in the modeling of expectations may lead to rejection of potentially valid theories and it may lead researchers to the use of models that would potentially be discarded under a different modeling of expectations (as an indicative example, non-rational expectations may allow standard theories to explain consumption and asset price behavior without recurring to new features as habit formation).

Amid recent trends in the literature toward progressively more sophisticated and comprehensive macroeconomic models, the rational expectations assumption is likely to become even stronger and its informational requirements even more stringent as the dimension and complexity of the models increase. In the three-equation New Keynesian model or in a basic RBC model à la Hansen (1985), the assumption of rational expectations may be a valid approximation. The model solution under rational expectations for the three-equation New Keynesian model, for example, resembles many VARs (with a similar set of variables) that have been estimated to identify the effects of monetary policy shocks and which are known to fit the data quite well. But in a medium-scale model à la Smets and Wouters, or its many extensions, agents under rational expectations are assumed to know a large number of coefficients, use a substantial number of state variables, and observe several disturbances, some of them not necessarily with simple interpretations, to form their expectations. Their implicit forecasting models, given by (24), in fact, easily contain more than a dozen regressors. The problem becomes even more serious in larger-scale models, and when the model includes additional variables, such as financial variables, as stock prices, exchange rates, and so forth, in which departures from rational expectations may be more pronounced. Misspecification in the formation of expectations anywhere in the large-scale model will unfortunately bias the rest of the coefficients.

Recently, structural rational expectations models have been also extended to include features such as regime switches in the coefficients at unknown times, time-varying structural coefficients, time-varying volatilities of the shocks, and so forth. Again maintaining the REH in those contexts may prove too stringent.

The paper by Milani and Rajbhandari (2012a), in this same issue, for example, highlights 
the sensitivity of the econometric properties of even a stylized benchmark New Keynesian model to the way expectations are modeled, with mechanisms ranging from rational expectations (with and without news) to non-fully-rational learning and subjective expectations. The results seem to suggest, at a minimum, a need in the literature for more checks of the results' sensitivity to alternative expectation formation schemes.

Future changes in the literature concerning the REH may be even deeper. Woodford (2011), in a non-technical interview on the methodology of macroeconomic theory, criticizes the postulate of rational expectations, based on internal consistency with the only existent model of the economy assumed by the researcher, and he goes on to predict that "The macroeconomics of the future, I believe, will still make use of general-equilibrium models in which the behavior of households and firms is derived from considerations of intertemporal optimality, but in which the optimization is relative to the evolving beliefs of those actors about the future, which need not perfectly coincide with the predictions of the economists model. ... But it will have to go beyond conventional latetwentieth-century methodology as well, by making the formation and revision of expectations an object of analysis in its own right, rather than treating this as something that should already be uniquely determined once the other elements of an economic model (specifications of preferences, technology, market structure, and government policies) have been settled.".

\section{Refinements of Rational Expectation Models}

We discuss here several extensions that maintain the rational expectations hypothesis intact, but that either assign a bigger role to fluctuations driven by expectational shifts (sunspots, news) or relax the informational assumptions to make the models more empirically realistic (imperfect knowledge, sticky information).

\subsection{Sunspots}

The empirical rational expectations DSGE literature typically imposes a dogmatic prior on the existence of multiple equilibria: the case of multiple equilibria receives a zero prior probability. Regions of indeterminacy are usually ruled out first by assuming priors on the parameters that ensure that, in the mixing, parameter draws only rarely imply the possibility of indeterminacy (for example, by assuming a prior on the Taylor rule response coefficient toward inflation that assigns either zero or low probability to values below one). In addition, every time a MH draw includes a combination of parameters that implies indeterminacy, the draw is rejected, and the chain is asked to generate a new draw. This procedure corresponds to imposing a dogmatic zero-probability prior 
on indeterminacy regions.

The determinacy or indeterminacy of the equilibrium in the model presented in Section 2 largely depends on a version of the Taylor principle similar to the one obtained in more stylized threeequation New Keynesian models. When the Taylor principle is not satisfied, for example because the central bank fails to respond aggressively enough to variation in inflation, expectations become a function of an external source of fluctuations, unrelated to fundamentals, and labeled a "sunspot" in the literature. Sunspots induce self-fulfilling fluctuations in the economy.

We have seen before that if a solution exists and is unique, the expectational errors $\eta_{t}$ can be expressed as a function of the structural shocks $\epsilon_{t}$ only. In the presence of indeterminacy, this is no longer true. In the full set of solutions, the expectational errors become a function of both the structural exogenous shocks (although with different coefficients) and of the sunspot shocks.

Lubik and Schorfheide (2003) show that linear rational expectations models can be written in the more general form in which multiple solutions may exist as

$$
\begin{array}{r}
\Gamma_{0} \xi_{t}=\Gamma_{1} \xi_{t-1}+\Psi \epsilon_{t}+\Pi \eta_{t}, \\
\eta_{t}=A_{1} \tilde{\eta}_{t}+A_{2} \zeta_{t}, \\
\tilde{\eta}_{t}=B_{1} \epsilon_{t}+B_{2} \zeta_{t},
\end{array}
$$

where $A_{1}, A_{2}, B_{1}, B_{2}$ are matrices of coefficients and, as discussed, expectational errors can now be solved as a function of fundamental and sunspot innovations:

$$
\eta_{t}=C_{1} \epsilon_{t}+C_{2} \zeta_{t} .
$$

Indeterminacy affects both the dependence of expectational errors on fundamental shocks (through $C_{1}$ being different from the corresponding matrix of coefficients under determinacy) and on nonfundamental sunspot shocks (which now have an effect on forecast errors).

As Lubik and Schorfheide (2004) show, the solution of the DSGE model under rational expectations can now be written as

$$
\xi_{t}=F \xi_{t-1}+(G+\Delta) \epsilon_{t}+\Lambda \zeta_{t} .
$$

Under determinacy, $\Delta=0$ and $\Lambda=0$. Indeterminacy, therefore, has two effects: it changes the propagation of structural shocks $\epsilon_{t}$, which is no longer uniquely pinned down in the model, and it leads to self-fulfilling fluctuations in the state variables $\xi_{t}$ driven by the sunspot shocks $\zeta_{t}$.

The literature on indeterminacy and sunspots in macroeconomics has been predominantly theoretical (e.g., Benhabib and Farmer, 1999). The main interest was to show that multiple equilibria 
and sunspots significantly improve the endogenous propagation properties of business cycle models, which are severely lacking under determinacy.

But recently, a number of papers have hinted at the possibility that indeterminacy, typically caused by the monetary policymaker's failure to satisfy the Taylor principle in New-Keynesian-style models, has been an empirically realistic feature of the U.S. economy, at least over portions of the post-World War II period. Clarida, Gali', and Gertler (2000) use a limited-information singleequation estimation to find that Federal Reserve's policy did not respect the Taylor principle in the pre-Volcker (pre-1979) sample: such a monetary policy rule, if inserted in a structural New Keynesian model, would have been a source of macroeconomic instability due to indeterminacy and sunspot-driven fluctuations. Lubik and Schorfheide (2004) use a Bayesian estimation of the full system of equations in the New Keynesian model and they extend the typical likelihood-based estimation approaches used for DSGE models to allow for positive probabilities on regions of indeterminacy. Their paper represents a major step forward in the empirical literature, since it avoids imposing dogmatic priors on the probabilities of indeterminacy versus determinacy. Their empirical results end up being in line with Clarida, Gali', and Gertler's conclusions. The parameter estimates and posterior model probabilities indicate that the Fed moved from a monetary policy behavior that failed to satisfy the Taylor principle during the pre-1979 period to a more aggressive policy that satisfied the Taylor principle in the post-1982 period. The model achieves highest posterior probability under indeterminacy in the first subsample, while determinacy allows to fit the data better in the second subsample. Treadwell (2010) finds similar results using data for the remaining countries in the G-7 over the post-war sample. Hirose (2008) estimates a financial accelerator model on Japanese data and he also shows that indeterminacy and sunspots are supported by the data.

Overall, indeterminacy may allow rational expectations models to fit macro data without resorting to various frictions, since they do a good job in endogenously generating persistence. They are also useful in breaking down the tight link between forecast errors under rational expectations and structural innovations, which may allow the model more degrees of freedom to fit the data.

Given the continuing predominance in the literature of papers that rule out the existence of indeterminacy, it is worth wondering whether there are instances in which the empirical conclusions would change if researchers departed from dogmatic priors on the probabilities of determinacy and indeterminacy. It seems that the evidence in medium-scale models as Smets and Wouters (2007) is not particularly supportive toward indeterminacy, but this may not be true in the more complicated models that add a number of additional frictions, especially regarding banking sectors or financial markets, as the evidence in Hirose (2008) appears to suggest. 


\subsection{News}

One recent important direction in the business cycle literature has been the introduction of "news". Typically, the DSGE literature assumes that shocks are entirely unanticipated by agents until they are realized and, therefore, observed. The literature on news changes the information structure in the models: agents can now receive news in some period $t$ about future shocks that will materialize only $h$ periods ahead. Disturbances, therefore, include both unanticipated and anticipated components. News can be fully realized $h$ periods later or they can fail to materialize, leading to revisions in expectations. News models are particularly attractive since such downward revisions in expectations may lead to volatility in the economy and create recessions: real business cycle models that allow for news, therefore, do not necessarily need volatile and often negative technology shocks to explain business cycles and recessions.

Beaudry and Portier (2006), in a very influential paper, provide empirical evidence from VAR models that an identified shock that does not affect total factor productivity in the long run, but that is almost perfectly correlated with the tfp shock (which does affect the economy in the long run), is an important driver of business cycle fluctuations. Motivated by their finding that this is a short-run shock, although correlated with long-run tfp, they interpret it as "news" about future technology.

A major drawback of early models with news is that they fail to match the comovement of the main business cycle variables in response to news shocks. Jaimovich and Rebelo (2009) advance the theory on news shocks by proposing a solution to the comovement problem: they show that a basic RBC model, if extended to include variable capital utilization, adjustment costs in investment, and a modified utility function with preferences that shut down the short-run wealth effect on labor supply, can match the business cycle comovement of output, consumption, investment, and hours, following a positive news shock about technology. The dynamics of business cycle models with news, issues in the literature, and proposed solutions, are clearly laid down in the survey by Lorenzoni (2011).

The previous works and a large part of the original literature on news focused on relatively stylized RBC models and almost exclusively on news about technology (Lorenzoni, 2009, is an exception considering news related to demand). But, more recently, news shocks have been inserted in larger scale DSGE models, under both flexible and sticky prices and wages, and with news that may refer to different types of shocks. Schmitt-Grohe' and Uribe (2012) model news and insert it in a medium-scale DSGE model with flexible prices, but augmented to include habit formation in consumption, habit formation in leisure, investment adjustment costs, variable capacity utilization, 
and, in some specifications, preferences as in Jaimovich and Rebelo (2009). They allow permanent and transitory technology shocks, permanent and transitory investment-specific shocks, transitory government spending shocks, wage markup shocks, and preference shocks; each shock includes both an unanticipated and an anticipated (news) component.

In their model, each structural disturbance is assumed to evolve as:

$$
\varepsilon_{t}=\rho \varepsilon_{t-1}+\epsilon_{t}^{0}+\epsilon_{t-4}^{4}+\epsilon_{t-8}^{8}
$$

where $\epsilon_{t}^{0}$ denotes a typical unanticipated innovation, while $\epsilon_{t-h}^{h}$ denotes news shocks that are known at time $t-h$ and materialize only $h$ periods ahead. The horizon of news may clearly vary: they choose to focus only on news for 4 and 8 quarters ahead in their paper, which should already include relevant anticipations at least for medium-term horizons (different horizon structures were also used in earlier versions of their work). An obvious way to select the relevant news horizons would be in terms of model fit: this is the approach followed in Fujiwara, Hirose, and Shintani (2011) and Milani and Treadwell (2012), who use Bayesian model comparison tools to verify the fit of a wide set of horizon combinations and to select 'optimal', or best-fitting, horizons.

The state-space system significantly expands with the addition of news. For each disturbance, the corresponding portion of the state space can be written as:

$$
\left[\begin{array}{c}
\varepsilon_{t} \\
\epsilon_{t}^{4} \\
\epsilon_{t-1}^{4} \\
\epsilon_{t-2}^{4} \\
\epsilon_{t-3}^{4} \\
\epsilon_{t}^{8} \\
\epsilon_{t-1}^{8} \\
\epsilon_{t-2}^{8} \\
\epsilon_{t-3}^{8} \\
\epsilon_{t-4}^{8} \\
\epsilon_{t-5}^{8} \\
\epsilon_{t-6}^{8} \\
\epsilon_{t-7}^{8}
\end{array}\right]=\left[\begin{array}{lllllllllllll}
\rho & 0 & 0 & 0 & 1 & 0 & 0 & 0 & 0 & 0 & 0 & 0 & 1 \\
0 & 0 & 0 & 0 & 0 & 0 & 0 & 0 & 0 & 0 & 0 & 0 & 0 \\
0 & 1 & 0 & 0 & 0 & 0 & 0 & 0 & 0 & 0 & 0 & 0 & 0 \\
0 & 0 & 1 & 0 & 0 & 0 & 0 & 0 & 0 & 0 & 0 & 0 & 0 \\
0 & 0 & 0 & 1 & 0 & 0 & 0 & 0 & 0 & 0 & 0 & 0 & 0 \\
0 & 0 & 0 & 0 & 0 & 0 & 0 & 0 & 0 & 0 & 0 & 0 & 0 \\
0 & 0 & 0 & 0 & 0 & 1 & 0 & 0 & 0 & 0 & 0 & 0 & 0 \\
0 & 0 & 0 & 0 & 0 & 0 & 1 & 0 & 0 & 0 & 0 & 0 & 0 \\
0 & 0 & 0 & 0 & 0 & 0 & 0 & 1 & 0 & 0 & 0 & 0 & 0 \\
0 & 0 & 0 & 0 & 0 & 0 & 0 & 0 & 1 & 0 & 0 & 0 & 0 \\
0 & 0 & 0 & 0 & 0 & 0 & 0 & 0 & 0 & 1 & 0 & 0 & 0 \\
0 & 0 & 0 & 0 & 0 & 0 & 0 & 0 & 0 & 0 & 1 & 0 & 0 \\
0 & 0 & 0 & 0 & 0 & 0 & 0 & 0 & 0 & 0 & 0 & 1 & 0
\end{array}\right]\left[\begin{array}{c}
\varepsilon_{t-1} \\
\epsilon_{t-1}^{4} \\
\epsilon_{t-2}^{4} \\
\epsilon_{t-3}^{4} \\
\epsilon_{t-4}^{4} \\
\epsilon_{t-1}^{8} \\
\epsilon_{t-2}^{8} \\
\epsilon_{t-3}^{8} \\
\epsilon_{t-4}^{8} \\
\epsilon_{t-5}^{8} \\
\epsilon_{t-6}^{8} \\
\epsilon_{t-7}^{8} \\
\epsilon_{t-8}^{8}
\end{array}\right]+\left[\begin{array}{ccc}
\sigma_{0} & 0 & 0 \\
0 & \sigma_{4} & 0 \\
0 & 0 & 0 \\
0 & 0 & 0 \\
0 & 0 & 0 \\
0 & 0 & \sigma_{8} \\
0 & 0 & 0 \\
0 & 0 & 0 \\
0 & 0 & 0 \\
0 & 0 & 0 \\
0 & 0 & 0 \\
0 & 0 & 0 \\
0 & 0 & 0
\end{array}\right]\left[\begin{array}{c}
\epsilon_{t}^{0} \\
\tilde{\epsilon}_{t}^{4} \\
\epsilon_{t}^{8}
\end{array}\right]
$$

where $\tilde{\epsilon}_{t}^{h}$ simply redefines the corresponding $\epsilon_{t}^{h}$ innovation, and the $\sigma_{h}$ coefficients denote standard deviations.

Schmitt-Grohe' and Uribe estimate the model using Bayesian methods. They also show a simulation exercise on artificial data to show that the standard deviation of news shocks are identified even under non-informative priors. News can therefore be disentangled from unanticipated shocks in the estimation. The identification of news, in particular, derives from the different impact that surprise and news shocks have on expectations of future macroeconomic variables, which need to be 
taken into account in most agents' optimization decisions. Unanticipated shocks are unforecastable and do not affect expectations. News, on the other hand, can be identified through their effect on future expectations. For example, expectations about future innovations can be expressed as:

$$
E_{t} \epsilon_{t+h}= \begin{cases}\epsilon_{t+h-4}^{4}+\epsilon_{t+h-8}^{8} & 1 \leq h \leq 4 \\ \epsilon_{t+h-8}^{8} & 4<h \leq 8 \\ 0 & h>8\end{cases}
$$

The model can then be solved under rational expectations to find a solution as (24).

Schmitt-Grohe' and Uribe find that a variety of news shocks combine to explain about half of output and other real variable fluctuations over the business cycle.

Similar approaches to introduce news are also followed in the paper by Fujiwara, Hirose, and Shintani (2011), and Khan and Tsoukalas (2011). The results in their cases are less supportive toward the so-called "news view" of the business cycle than those obtained in the previous paper. They both estimate medium-scale DSGE models with sticky prices, sticky wages (whereas SchmittGrohe' and Uribe's paper focused on a flexible-price specification in the RBC tradition), à la Smets and Wouters (2007). It is certainly worth investigating in more detail in future research to what extent different model features affect the estimated impact of news shocks and the reasons behind the differences. Barsky and Sims (2010) are also more critical toward the news literature by finding that news shocks fail to explain most of the recent U.S. recessions, although using a VAR, rather than a fully-fledged DSGE, model.

Various other papers have now studied the empirical role of news on macroeconomic outcomes. Milani and Treadwell (2012) allow for both unanticipated ("surprise") and anticipated ("news") components in monetary policy shocks, which are not considered in the other papers. News about monetary policy seems natural given the effort by policy makers to manage private-sector expectations, central banks' emphasis on policy announcements, transparency, and communication, and the effort by the private sector to anticipate future policy decisions. They find that news plays a larger role than monetary policy surprises on the variability of output and that the introduction of news changes the shape of impulse responses to monetary policy shocks: output is shown to respond less and more quickly to unanticipated policy shocks than typically found in the literature. The response to anticipated policy changes is, instead, larger and more persistent. Avdjiev (2011) illustrates how adding data on asset prices changes many of the empirical conclusions in estimated DSGE models with news-driven fluctuations. News shocks are now considered also in less traditional frameworks, moving away from news only about technology: Gomes and Mendicino (2012), for example, consider news related to the housing market and show that news accounts for a large fraction of house price variation. 
The literature on introducing news in DSGE models is still young and rapidly expanding. A number of new papers are adding them in a variety of frameworks. The jury is still out on whether news represents a major source of economic fluctuations or not.

\subsection{Limitations on Knowledge}

The treatment of rational expectations has so far assumed full knowledge by economic agents. Although this is by far the most common case, the literature has recognized that limitations on the degree of knowledge can add elements of realism to the models, while remaining within the realm of rational expectations.

Among others, we point out the work by Schorfheide (2005), who allows for imperfect knowledge about the monetary authority's inflation target, by modeling agents that need to learn about its fluctuating value over time. While the model with perfect information still fits the data better, the limited information model better captures important episodes as the disinflation experience in the early 1980s.

Levine et al. (2010) recognize that agents may not have full information about all the state variables in the system and about the disturbances hitting the economy. They build and estimate a model in which agents need to solve real-time filtering problems in order to infer the values of the state variables and shocks. Their approach breaks the asymmetry between information available to the econometrician, who uses only few observables in the estimation, and the economic agents in the model, who, typically, under rational expectations, dispose of much wider information sets. They show that the model with imperfect information creates endogenous realistic degrees of persistence, which allow it to fit the data well without standard mechanisms as habit formation and indexation.

Although more complicated, models in this spirit, which imply symmetric information between agents in the model and econometrician while retaining the REH, are clearly a promising avenue for future empirical research.

\subsection{Sticky Information}

Another popular alternative to extend the modeling of expectations, while keeping the benchmark rational expectations hypothesis, is through the assumption of sticky information. In the simplest specification, agents are assumed to update their information only with some probability $\lambda$ in each period. On average, therefore, they update their information sets only once every $1 /(1-\lambda)$ periods. Mankiw and Reis (2002) introduce the sticky-information Phillips curve, based on the above-mentioned Calvo-style updating scheme for information. Reis, however, in a set of papers (e.g., Reis 2006a,b) provides deeper microfoundations for models with sticky information. 
Turning to the empirical literature, several papers are interested in comparing models including inflation equations based on sticky prices with those based on sticky information. In particular, sticky-information alternatives are considered in the literature for their role in generating persistence in inflation that can match the persistence in actual data. In this survey, however, we are more interested in the empirical evidence regarding DSGE models, rather than that based on singleequations.

Estimations of comprehensive DSGE models under sticky information exist, but they are few. Paustian and Pytlarczyk (2006), for example, estimate DSGE variants under Calvo price-setting and sticky information. They show that the standard model under Calvo strongly dominates the alternative. Trabandt (2007) finds that the two models do equally well, while Korenok's (2004) results also favor the sticky-price model. Overall, the results from the literature comparing New Keynesian Phillips curves obtained under sticky prices with the sticky-information Phillips curve are mixed, with the balance tipping in favor of sticky-price models.

Only few papers estimate full general equilibrium models that incorporate sticky information in all the relevant decisions in the model economy. The first papers to do this are those by Mankiw and Reis (2007) and Reis (2009a,b), who consider a benchmark neoclassical model with flexible prices and introduce inattention regarding the consumption/saving, price setting, and wage setting decisions. There aren't, instead, many comparisons between DSGE models under pervasive sticky information and alternative models. From an empirical point of view, it is possible that a more satisfactory specification is likely to include both sticky prices and sticky information and maybe some of the frictions considered in Smets and Wouters (2007).

\section{Departures from Rational Expectations: Adaptive Learning}

Agents under rational expectations have no incentives to revise their beliefs, since they already have full knowledge about the structure of the economy. A large literature on adaptive learning has asked whether agents would converge to the same equilibrium that exists under rational expectations if agents started with a more limited degree of knowledge and were allowed to learn over time using historical time series observations on the variables of interest. Agents would behave as econometricians by using available data and running simple regressions to form their beliefs, update their estimates, and obtain forecasts about the values of the aggregate variables that they need to solve their current optimization problems. Comprehensive introductions to adaptive learning models and literature are offered in Evans and Honkapohja (1999, 2001).

For almost three decades, the learning literature has mostly focused on the convergence proper- 
ties of economic systems under learning to the rational expectations equilibrium, on evaluating the plausibility of the $\mathrm{REH}$, and on providing a selection device to choose among multiple equilibria. More rarely, the studies focused on the role of learning during the transition period, for example in response to changes in policy or during particular economic times (e.g., Marcet and Nicolini, 2003, stress the importance of departures from rational expectations and learning to generate hyperinflations in a Cagan-type monetary model).

More recently, an increasing number of papers has started studying at more depths the empirical role of transitional dynamics due to learning behavior and the effects of learning on business cycle models. Using simulation evidence, Williams (2004) tests the effects of adaptive learning in benchmark RBC and New Keynesian models and compares the implied moments with those obtained under rational expectations. He shows that while learning has small effects in an RBC setting, the effects are larger in the New Keynesian model.

Estimated general equilibrium models under learning have also become more common in recent years. Milani (2007) estimates a benchmark New Keynesian model extended to include "mechanical" sources of persistence as habit formation in private expenditures and indexation to past inflation in price setting. The paper shows that when the conventional assumption of rational expectations is relaxed to assume learning by economic agents, the estimated degrees of habit formation and indexation that are necessary to fit the data fall from values close to one to values close to zero. The results suggest that learning can induce realistic levels of persistence in the models, so that mechanical sources of persistence may be omitted. Moreover, the posterior model probabilities show that the model with learning fits the data better than the model with rational expectations does.

In the same spirit as the previously discussed work by Levine et al. (2010), also under learning, the informational differences between the researcher/econometrician estimating the model and the agents within the model are removed. While agents enjoy an informational advantage under rational expectations, under learning, they are assumed to have the same, more limited, knowledge that an econometrician working with the model would have: therefore, agents lack knowledge about the parameters of the model, they may lack knowledge about the current values of the shocks, and so forth. The deviation from rational expectations, however, is kept minimal. Agents still know the structural form of the model solution, i.e. they use a correctly-specified model that has the same regressors as the model solution under rational expectations. Therefore, expectations, while not-fully rational, are typically interpreted as near-rational. 
The model with near-rational expectations can be written in state space form as

$$
A_{0} \xi_{t}=A_{1} \xi_{t-1}+A_{2} \widehat{E}_{t-1} \xi_{t+1}+D \epsilon_{t}
$$

where $\xi_{t}=\left[\Gamma_{t}, \varepsilon_{t}, \tilde{\Gamma}_{t-1}\right]^{\prime}$ using the same notation previously used for the rational expectations model. We assume here $t-1$ timing in the agents' information set when forming their expectations.

Under a model as (1)-(14), agents would estimate a linear model, which constitutes their Perceived Law of Motion (PLM)

$$
\xi_{t}=a_{t}+b_{t} \xi_{t-1}+v_{t}
$$

where $a_{t}$ and $b_{t}$ are vectors and matrices of beliefs about the reduced-form coefficients. The beliefs are recursively updated following a constant-gain learning algorithm as

$$
\begin{aligned}
\widehat{\phi}_{t} & =\widehat{\phi}_{t-1}+\overline{\mathbf{g}} R_{t}^{-1} \chi_{t}\left(\xi_{t}-\chi_{t}^{\prime} \widehat{\phi}_{t-1}\right) \\
R_{t} & =R_{t-1}+\overline{\mathbf{g}}\left(\chi_{t} \chi_{t}^{\prime}-R_{t-1}\right)
\end{aligned}
$$

where $\chi_{t} \equiv\left\{1, \xi_{t-1}\right\}$, and $\widehat{\phi}_{t}=\left[a_{t}^{\prime}, b_{t}^{\prime}\right]^{\prime}$. Equation (35) describes the updating of beliefs regarding the model solution coefficients, while equation (36) describes the updating of the variance-covariance matrix $R_{t}$ of the associated regressors in $\chi_{t}$. Beliefs at each point in time $t$ are, therefore, equal to their value in the previous period plus an adjustment in the direction of the most recent forecast error. A key coefficient in models with learning is given by the constant-gain coefficient $\overline{\mathbf{g}}$, which dictates the speed at which beliefs are revised in light of new information.

Using the available information and the updated beliefs, expectations are formed as

$$
E_{t-1} \xi_{t+1}=\left(I+\widehat{b}_{t-1}\right) \widehat{a}_{t-1}+\widehat{b}_{t-1}^{2} \xi_{t-1}
$$

The resulting expectations can be substituted into the original model, yielding the Actual Law of Motion of the economy, or ALM, which, in state-space form, is given by:

$$
\xi_{t}=A_{t}+F_{t} \xi_{t-1}+G w_{t}
$$

The model has similar form to the solution obtained under rational expectations, but the matrix of coefficients $F_{t}$ is now time-varying and the vector of intercepts is now allowed to be different from 0 (the value it would have under rational expectations) and it is also time-varying.

In addition to the paper described above, a number of other papers show the usefulness of modeling learning in the formation of expectations to fit macroeconomic data. Milani (2006) follows Preston (2005)'s approach by deriving a model with subjective expectations in which longhorizon forecasts about output, inflation, and interest rates matter. He shows that mechanical 
sources of persistence still become superfluous under learning. ${ }^{6}$ Some of the empirical results that are typically found under the assumption of rational expectations may be sensitive the way expectations are modeled: Milani (2008a) shows that the evidence on the Federal Reserve's failure to satisfy the Taylor principle in the 1970s, which is found in Lubik and Schorfheide (2004), for example, doesn't carry through in models that allow for revisions in beliefs and learning. Along the same lines are the results in Milani (2009c): while many papers find evidence of large time-variation in the exogenous inflation target that the Federal Reserve implicitly follows when the models are estimated under the assumption of rational expectations, the estimated time-varying target is much less variable and always close to $2.5 \%$ when knowledge about the economy is imperfect and beliefs are allowed to be updated over time. Primiceri (2006), Sargent, Williams, and Zha (2006), and Best (2010) model, instead, learning by the policymaker, rather than by the private-sector, and show that evolving beliefs about the state of the economy helps explaining U.S. monetary policy decisions over the post-war sample.

The previous papers typically introduce learning in small-scale New Keynesian models. Slobodyan and Wouters (2012), instead, consider learning in medium-scale DSGE models à la Smets and Wouters. They show that learning improves the fit of the model compared with the benchmark case of rational expectations. Eusepi and Preston (2008) estimate a baseline RBC model under long-horizon expectations and learning. Again learning plays an important role, although possibly not as large as in monetary models of the business cycle. They show that the model is able to fit the data even assuming a technology shock that is $20-30 \%$ less volatile than it would need to be under rational expectations. This is important since the need for highly volatile technology shocks seems to be at odds with real-world evidence.

The empirical literature has usually assumed learning by agents with a constant gain. Old observations are discounted more heavily than more recent ones. Constant-gain learning is believed to work well in mimicking the behavior of forecasters that are worried about structural change in the parameters of the economy. The case of recursive-least-squares learning, where the gain is decreasing rather than constant, is standard in the theoretical literature, but less common in empirical work. One of the results emerging from the previous set of studies regards the evidence on the values of the gain that provide a better fit of the macro data. Most of the papers indicate that values around 0.02 (implying that observations in $t-1, t-2, \ldots, t-k$, are weighted as $(1-0.02)$, $\left.(1-0.02)^{2}, \ldots,(1-0.02)^{k}\right)$, for quarterly data, are more realistic. The empirical estimates are thus consistent with those typically used in theoretical and calibrated studies.

\footnotetext{
${ }^{6}$ Milani (2009a) verifies whether the results are similar on Euro area data, finding more evidence of intrinsic persistence than in the U.S.
} 
An even better fit, however, may be obtained by allowing more flexible specifications of the gain, for example, by assuming that the gain is time-varying and that its size adjusts endogenously to economic developments and past forecast errors (e.g., Milani, 2008c, following Marcet and Nicolini, 2003).

Finally, learning may be useful for situations in which it is important to capture time-variations in the responses of the economy to shocks. Milani (2009b), for example, shows that evolving private-sector beliefs and learning can account for the empirical observation that oil price shocks seemed to cause large changes in output and inflation in the 1970s (in large part through selffulfilling expectational effects), while shocks of similar magnitude generate only modest effects in the recent decade. The paper shows that an estimated general equilibrium model with an energy input and allowing for learning can rationalize the attenuation of the effects of oil price shocks, which is, instead, harder to capture through other explanations. Milani (2008b) also shows that the transmission of non-fundamental stock market shocks on the real economy has also varied over the sample as a result of different effects on beliefs.

From a theoretical point of view, Woodford (2010) studies the robust optimal monetary policy in the case of departures from model-consistent rational expectations. Given the uncertainty on the way private-sector expectations respond to policies and economic developments, these investigations should become more and more common.

While learning has proved useful both in theory and in the estimation of macroeconomic models, it is still an open question whether the assumed learning behavior is consistent with behavior at a more microeconomic level. Although some papers have started investigating the issue (e.g., Baranowski, 2011), more evidence on learning behavior on individual data is definitely needed.

\subsection{More Drastic Departures from Rational Expectations}

Models with adaptive learning assume deviations from rationality that remain on purpose limited. Other models assume deviations that are more drastic: for example, models that assume "heuristic" behavior in the formation of expectations. A recent paper by De Grauwe (2011) assumes heuristics by having agents who forecast by switching between two simple misspecified and biased rules: one that is consistently overly optimistic and the other that is overly pessimistic. De Grauwe inserts the forecasting rules in a New Keynesian model and he provides simulation evidence showing that heuristics leads to booms and busts driven by those waves of optimism and pessimism. Jang and Sacht (2012) estimate the model using moment-based methods.

These models are very recent and the corresponding literature still limited. I won't discuss 
them in larger detail in this survey.

\section{Exploiting Observed Expectations form Surveys}

One way to test whether the rational expectation hypothesis gives a valid approximation of the way forecasters in the economy form expectations is to look at the evidence from surveys. Direct data on subjective expectations from surveys have suscitated interest for a long time. The various uses of expectations in testing the REH are already discussed in Pesaran (1987) and in the Handbook chapter by Pesaran and Wheale (2006). Several studies use subjective expectations data to test the hypothesis of rational expectations, either in the aggregate, or at the individual level and using panel estimation (e.g., Keane and Runkle, 1990). Roberts (1997) and Adam and Padula (2011), among others, add subjective expectations to New Keynesian Phillips curves that are estimated using single equation methods. They show that subjective expectations may be a source of inflation persistence.

Observed expectations, however, have not been exploited very often in the context of fullyfledged general equilibrium macroeconomic models, where rational expectations are typically assumed.

Recently, direct expectations from surveys have started being used more often in those contexts as well. Del Negro and Eusepi (2011) investigate whether a conventional DSGE model under rational expectations (with both perfect or imperfect information) is able to generate expected inflation series that match inflation forecasts from surveys. Aruoba and Schorfheide (2011) add survey inflation forecasts to their observables as additional information that can be used to infer the time-varying Fed's inflation target. Ormeno (2010) uses survey inflation expectations to discipline the estimation of models with learning of the type described in the previous section. Milani (2011, 2012) exploits a larger set of observed expectations to also estimate models with learning, but with the main interest of extracting expectation, or sentiment, shocks and analyze their contribution over the business cycle. Expectation/sentiment shocks are modeled by changing (37) to allow for excesses of unjustified optimism and pessimism in the formation of expectations, as

$$
E_{t-1} \xi_{t+1}=\left(I+\widehat{b}_{t-1}\right) \widehat{a}_{t-1}+\widehat{b}_{t-1}^{2} \xi_{t-1}+e_{t}
$$

where $e_{t}$ defines the novel shocks. The papers conclude that sentiment shocks are a major driver of business cycle fluctuations, explaining up to half of the variability in output. The addition of a variety of expectations data is likely to be a promising and worthwhile area of future research for learning models. 
Expectations data, however, can be used not only to discipline the estimation of models with learning or to check whether some of the implied expectation series under rational expectations are consistent with survey data, but also to discipline the estimation of rational expectation models. The information contained in expectations can allow researchers to better estimate not only expectations themselves, but also the structural shocks in the model, news, as well as structural parameters.

Steps in this direction are taken in Milani and Rajbhandari (2012b). They force rational expectations to be consistent with a large set of subjective expectations from surveys, spanning different forecasting horizons. In particular, that paper is interested in exploiting observed expectations to help in the extraction and identification of a variety of news shocks. Cole and Milani (2012) use a DSGE-VAR approach that includes observed data on expectations to investigate whether the hypothesis of rational expectations is severely misspecified in a monetary DSGE model and to find out where exactly such misspecification is more serious.

Survey expectations are being exploited more frequently in the evaluation of DSGE models. The use of observed expectations may allow researchers to retain the modeling advantages of rational expectations, while at the same time improving their empirical realism by requiring them to match the available expectations series as closely as possible. We regard this line of research as particularly promising.

Finally, we would like to mention that the use of survey expectations may be used to accommodate the existence of heterogeneous expectations in the model. This survey has sidestepped, as most of the literature, the possibility of heterogeneous expectations. Heterogeneity, uncertainty, and disagreement in the formation of expectations may, however, turn out being of primary importance for understanding aggregate fluctuations. ${ }^{7}$

\section{Conclusions}

The rational expectations hypothesis has served as a building block for theoretical and empirical macroeconomic research for the last forty years. It has been widely successful.

Rational expectations DSGE models are now routinely developed and confronted with data in academic and policy-making institutions across the world. While empirical setbacks of rational expectations models have been numerous, the current generation of structural DSGE models, join-

\footnotetext{
${ }^{7}$ A simple way to introduce heterogeneous expectations is to assume that different fractions of agents form expectations that correspond to either rational, naïve, or near-rational through learning. Levine et al. (2010) provide an example by studying a model with an estimated fraction of agents that are allowed to form adaptive, rather than rational, expectations.
} 
ing the better elements of RBC and New Keynesian approaches, has been particularly effective in matching macro data.

This survey, however, has also pointed out various empirical problems related to the rational expectations hypothesis, and it has presented an overview of some of the most popular extensions and alternatives in the literature. Given the pervasive uncertainty surrounding the formation of expectations, it is probably necessary that the macroeconomic literature starts to consistently check the sensitivity of the empirical conclusions that are obtained under rational expectations to even minimal departures from the benchmark REH.

A recent direction seems to move toward allowing expectations and shocks to expectations to directly cause business cycle fluctuations: the corresponding models emphasize expectations-driven business cycles, sometimes driven by psychological factors, which were already discussed by classic economists of the past as Pigou (1927), Keynes (1936), and Haberler (1937).

Finally, the survey has manifested the wish that even in the cases in which the REH is preserved, model-consistent expectations should be required to conform as closely as possible to the corresponding expectations series from surveys or other sources. 


\section{References}

[1] Klaus, K., and M. Padula, 2011. "Inflation Dynamics And Subjective Expectations In The United States," Economic Inquiry, vol. 49(1), pages 13-25.

[2] Altissimo, F., Ehrmann, M., and F. Smets, 2006. "Inflation persistence and price-setting behaviour in the euro area a summary of the IPN evidence," Occasional Paper Series 46, European Central Bank.

[3] An, S., and F. Schorfheide, 2007. "Bayesian Analysis of DSGE Models," Econometric Reviews, vol. 26(2-4), pages 113-172.

[4] Aruoba, B., and F. Schorfheide, 2011. "Sticky Prices versus Monetary Frictions: An Estimation of Policy Trade-Offs," American Economic Journal: Macroeconomics, vol. 3(1), pages 60-90.

[5] Avdjiev, S., 2011. "News Driven Business Cycles and Data on Asset Prices in Estimated DSGE Models." BIS Working Papers No 358.

[6] Baranowski, R., 2011. "An Empirical Analysis of Adaptive Learning Among Individual Professional Forecasters", mimeo, UC Irvine.

[7] Barsky, R.B., and E.R. Sims, 2009. "News Shocks," NBER Working Papers 15312.

[8] Beaudry, P., and F. Portier, 2006. "Stock Prices, News, and Economic Fluctuations," American Economic Review, vol. 96(4), pages 1293-1307.

[9] Benhabib, J., and R.E.A. Farmer, 1999. "Indeterminacy and sunspots in macroeconomics," Handbook of Macroeconomics, in: J. B. Taylor and M. Woodford (ed.), edition 1, volume 1, chapter 6, pages 387-448, Amsterdam: Elsevier.

[10] Best, G., 2010. "Policy Preferences and Policymakers Beliefs: The Great Inflation", mimeo, California State University, Fullerton.

[11] Beyer, A., and R.E.A. Farmer, 2004. "On the indeterminacy of New-Keynesian economics," Working Paper Series 323, European Central Bank.

[12] Blanchard, O.J., and C.M. Kahn, 1980. "The Solution of Linear Difference Models under Rational Expectations," Econometrica, vol. 48(5), pages 1305-11.

[13] Branch, W.A., 2004. "The theory of rationally heterogeneous expectations: evidence from survey data on inflation expectations," Economic Journal, 114 (497), 592621.

[14] Branch, W.A., 2007. "Sticky information and model uncertainty in survey data on inflation expectations," Journal of Economic Dynamics and Control, 31, 245276.

[15] Cagan, P., 1956. "The Monetary Dynamics of Hyperinflation", in Friedman, Milton (ed.), Studies in the Quantity Theory of Money. Chicago: University of Chicago Press.

[16] Canova, F., and L. Sala, 2009. "Back to square one: Identification issues in DSGE models," Journal of Monetary Economics, vol. 56(4), pages 431-449.

[17] Christiano, L.J., Eichenbaum, M., and C.L. Evans, 2005. "Nominal Rigidities and the Dynamic Effects of a Shock to Monetary Policy." Journal of Political Economy 113, 1-45.

[18] Clarida, R., Gal, J., and M. Gertler, 2000. "Monetary Policy Rules And Macroeconomic Stability: Evidence And Some Theory," The Quarterly Journal of Economics, vol. 115(1), pages $147-180$.

[19] Cogley, T., and T.J. Sargent, 2008. "Anticipated Utility And Rational Expectations As Approximations Of Bayesian Decision Making," International Economic Review, vol. 49(1), pages $185-221$. 
[20] Cole, S., and F. Milani, 2012. "How Well Do New Keynesian Models Capture the Interaction Between Expectations and Macroeconomic Variables: A DSGE-VAR Approach", mimeo, UC Irvine.

[21] De Grauwe, P., 2011. "Animal spirits and monetary policy," Economic Theory, vol. 47(2), pages 423-457.

[22] Del Negro, M., and S. Eusepi, (2011). "Fitting Observed Inflation Expectations", Journal of Economic Dynamics and Control, 35(12), 21052131.

[23] Del Negro, M., and F. Schorfheide, 2011. "Bayesian Macroeconometrics", The Oxford Handbook of Bayesian Econometrics, eds. John Geweke, Gary Koop, and Herman van Dijk, Oxford: Oxford University Press.

[24] Dynan, K.E., 2000. "Habit Formation in Consumer Preferences: Evidence from Panel Data," American Economic Review, vol. 90(3), pages 391-406.

[25] Evans, G.W., and S. Honkapohja, 1999. "Learning dynamics," Handbook of Macroeconomics, in: J. B. Taylor and M. Woodford (ed.), Handbook of Macroeconomics, edition 1, volume 1, chapter 7, pages 449-542, Amsterdam: Elsevier.

[26] Evans, G.W, and S. Honkapohja, 2001. Learning and Expectations in Economics. Princeton University Press, Princeton, NJ.

[27] Eusepi, S., and B. Preston, 2011. "Expectations, Learning, and Business Cycle Fluctuations," American Economic Review, vol. 101(6), pages 2844-72.

[28] Fernndez-Villaverde, J., Guerron, P., and J. Rubio-Ramrez, 2010. "The New Macroeconometrics: A Bayesian Approach", in A. O'Hagan and M. West, eds., Handbook of Applied Bayesian Analysis, Oxford: Oxford University Press.

[29] Fernndez-Villaverde, and J. Rubio-Ramrez, 2007. "Estimating Macroeconomic Models: A Likelihood Approach," Review of Economic Studies, vol. 74(4), pages 1059-1087.

[30] Fisher, I., assisted by Harry G. Brown, 1911. The Purchasing Power of Money, its Determination and Relation to Credit, Interest and Crises, New York: Macmillan.

[31] Fisher, I., 193). The Theory of Interest. New York: Macmillan.

[32] Friedman, M., 1957. A Theory of the Consumption Function, Princeton: Princeton University Press.

[33] Fujiwara, I., Hirose, Y., and M. Shintani, 2011. "Can News Be a Major Source of Aggregate Fluctuations? A Bayesian DSGE Approach." Journal of Money, Credit and Banking 43(1), 129 .

[34] Gali, J., and M. Gertler, 1999. "Inflation dynamics: A structural econometric analysis," Journal of Monetary Economics, vol. 44(2), pages 195-222.

[35] Gomes, S., and C. Mendicino, 2011. "Housing Market Dynamics: Any News?," Working Papers w201121, Banco de Portugal.

[36] Haberler, G., 1937. Prosperity and Depression: A Theoretical Analysis of Cyclical Movements. Geneva: League of Nations.

[37] Hall, R.E., 1978. "Stochastic implications of the life cycle-permanent income hypothesis". Journal of Political Economy, 86 (6), pp. 971-87.

[38] Hansen, G.D., 1985. "Indivisible labor and the business cycle," Journal of Monetary Economics, vol. 16(3), pages 309-327.

[39] Hansen, L.P., 1982. "Large Sample Properties of Generalized Method of Moments Estimators." Econometrica, 50(4), pp. 1029-54. 
[40] Hansen, L.P., and K. J. Singleton, 1982. "Generalized Instrumental Variables Estimation of Nonlinear Rational Expectations Models," Econometrica, 50, 1269-1286

[41] L. P. Hansen and K. J. Singleton, 1983. "Stochastic Consumption, Risk Aversion, and the Temporal Behavior of Asset Returns." Journal of Political Economy, 91(2), pp. 249-65.

[42] Hirose, Y., 2008. "Equilibrium Indeterminacy and Asset Price Fluctuation in Japan: a Bayesian Investigation," Journal of Money, Credit, and Banking, 40(5).

[43] Ireland, P.N., 2004. "A method for taking models to the data," Journal of Economic Dynamics and Control, vol. 28(6), pages 1205-1226.

[44] Jaimovich, N., and S. Rebelo, 2009. "Can News about the Future Drive the Business Cycle?," American Economic Review, vol. 99(4), 1097-1118.

[45] Jang, T.-S., and S. Sacht, 2012. "Identification of Animal Spirits in a Bounded Rationality Model: An Application to the Euro Area," mimeo, University of Kiel.

[46] Kaldor, N., 1938. "The Cobweb Theorem", Quarterly Journal of Economics, Vol. 52, No. 2, pp. 255280.

[47] Keane, M., and D.E. Runkle, 1990. "Testing the Rationality of Price Forecasts: New Evidence from Panel Data," American Economic Review, Vol. 80, No. 4, pp. 714-735.

[48] Keynes, J. M., (1936). The General Theory of Employment, Interest and Money. MacMillan and Co, London, U.K.

[49] Khan, H.U., and J. Tsoukalas, 2011. "The Quantitative Importance of News Shocks in Estimated DSGE Models." Journal of Money, Credit and Banking, forthcoming.

[50] Korenok, O., 2008. "Empirical comparison of sticky price and sticky information models," Journal of Macroeconomics, vol. 30(3), pages 906-927.

[51] Kydland, F., and E.C. Prescott, 1982. "Time to Build and Aggregate Fluctuations". Econometrica, 50(6), 13451370.

[52] Levine, P., Pearlman, J., Perendia, G., and B. Yang, 2010. "Endogenous Persistence in an Estimated DSGE Model under Imperfect Information," CDMA Working Paper Series 1002.

[53] Linde', J., 2005. "Estimating New-Keynesian Phillips curves: A full information maximum likelihood approach," Journal of Monetary Economics, vol. 52(6), pages 1135-1149.

[54] Lorenzoni, G., (2009). "A Theory of Demand Shocks," American Economic Review, vol. 99(5), pages $2050-84$.

[55] Lorenzoni, G., (2011). "News and Aggregate Demand Shocks", Annual Review of Economics, Vol. 3: $537-557$.

[56] Lubik, T.A., and F. Schorfheide, 2003. "Computing sunspot equilibria in linear rational expectations models", Journal of Economic Dynamics and Control, 28(2), 273285.

[57] Lubik, T.A., and F. Schorfheide, 2004. "Testing for Indeterminacy: An Application to U.S. Monetary Policy," American Economic Review, vol. 94(1), pages 190-217.

[58] Lucas, R.E., 1976. "Econometric policy evaluation: A critique," Carnegie-Rochester Conference Series on Public Policy, vol. 1(1), pages 19-46.

[59] Mankiw, G.N., and R. Reis, 2002. "Sticky Information Versus Sticky Prices: A Proposal To Replace The New Keynesian Phillips Curve," The Quarterly Journal of Economics, vol. 117(4), pages 1295-1328.

[60] Mankiw, G.N., and R. Reis, 2007. "Sticky Information in General Equilibrium," Journal of the European Economic Association, vol. 5(2-3), pages 603-613. 
[61] Mankiw, G.N., Reis, R., and J. Wolfers, 2003. "Disagreement about Inflation Expectations," NBER Working Papers 9796, National Bureau of Economic Research.

[62] Marcet, A., and J.P. Nicolini, 2003. "Recurrent Hyperinflations and Learning," American Economic Review, vol. 93(5), pages 1476-1498.

[63] Marshall, A., 1890. Principles of Economics. London: McMillan.

[64] Milani, F., 2006. "A Bayesian DSGE Model with Infinite-Horizon Learning: Do "Mechanical" Sources of Persistence Become Superfluous?", International Journal of Central Banking, vol. 2(3), pp. 87-106.

[65] Milani, F., 2007. "Expectations, Learning and Macroeconomic Persistence", Journal of Monetary Economics, Volume 54, Issue 7, October 2007, Pages 2065-2082.

[66] Milani, F., 2008a. "Learning, Monetary Policy Rules, and Macroeconomic Stability", Journal of Economic Dynamics and Control, Vol. 32, No. 10, pages 3148-3165.

[67] Milani, F., 2008b. "Learning about the Interdependence between the Macroeconomy and the Stock Market", mimeo, UC Irvine.

[68] Milani, F., 2008c. "Learning and Time-Varying Macroeconomic Volatility", mimeo, UC Irvine.

[69] Milani, F., 2009a. "Adaptive Learning and Macroeconomic Inertia in the Euro Area", Journal of Common Market Studies, Volume 47, Issue 3, pp. 579-599.

[70] Milani, F., 2009b. "Expectations, Learning, and the Changing Relationship between Oil Prices and the Macroeconomy", Energy Economics, Volume 31, Issue 6, pages 827-837.

[71] Milani, F., 2009c. "Learning and the Evolution of the Fed's Inflation Target", mimeo, UC Irvine.

[72] Milani, F., 2011. "Expectation Shocks and Learning as Drivers of the Business Cycle", Economic Journal, Vol. 121, Iss. 552, pages 379-401.

[73] Milani, F., 2012. "Sentiment and the U.S. Business Cycle", mimeo, UC Irvine.

[74] Milani, F., and A. Rajbhandari, 2012a. "Expectation Formation and Monetary DSGE Models: Beyond the Rational Expectations Paradigm", Advances in Econometrics, this issue.

[75] Milani, F., and A. Rajbhandari, 2012b. "Observed Expectations, News Shocks, and the Business Cycle", mimeo, UC Irvine.

[76] Milani, F., and J. Treadwell, 2012. "The Effects of Monetary Policy "News" and "Surprises"”, forthcoming, Journal of Money, Credit and Banking, 2012.

[77] Muth, J.A., 1961. "Rational Expectations and the Theory of Price Movements." Econometrica, 29 , no. 6 (1961): 315-35.

[78] Nakamura, E., and J. Steinsson, 2008. "Five Facts about Prices: A Reevaluation of Menu Cost Models," The Quarterly Journal of Economics, vol. 123(4), pages 1415-1464.

[79] Ormeno, A., (2010). "Disciplining Expectations: Using Survey Data in Learning Models," mimeo, Universitat Pompeu Fabra.

[80] Paustian, M., and E. Pytlarczyk, 2006. "Sticky contracts or sticky information? Evidence from an estimated Euro area DSGE model," mimeo, Bank of England.

[81] Pesaran, M.H., 1987. The Limits to Rational Expectations, Oxford and New York: Blackwell Publishing.

[82] Pesaran, M.H., and M. Weale, 2006. "Survey Expectations," Handbook of Economic Forecasting, Amsterdam: Elsevier. 
[83] Pigou, A.C., (1927). Industrial Fluctuations. MacMillan, London, U.K.

[84] Poirier, D. (1998), Revising Beliefs in Nonidentified Models," Econometric Theory, 14(4), 483509 .

[85] Preston, B., 2005. "Learning about Monetary Policy Rules when Long-Horizon Expectations Matter," International Journal of Central Banking, vol. 1(2).

[86] Primiceri, G., 2006. "Why Inflation Rose and Fell: Policymakers' Beliefs and U.S. Postwar Stabilization Policy," Quarterly Journal of Economics, Vol. 121(3), 867-901.

[87] Reis, R., 2006a. Inattentive Consumers, Journal of Monetary Economics 53: 1761-1800.

[88] Reis, R., 2006b. "Inattentive Producers," Review of Economic Studies, vol. 73(3), pages 793821.

[89] Reis, R., 2009a. "Optimal Monetary Policy Rules in an Estimated Sticky-Information Model," American Economic Journal: Macroeconomics, vol. 1(2), pages 1-28.

[90] Reis, R., 2009b, ".A Sticky-information General Equilibrium Model for Policy Analysis". In: K. Schmidt-Hebbel, C. Walsh, and N. Loayza (eds.): Monetary Policy under Uncertainty and Learning, Vol. 13, Chapter 8, pp. 227-283.

[91] Roberts, J.M., 1997. "Is Inflation Sticky?" Journal of Monetary Economics, vol. 39, no. 2, pp. $173-196$

[92] Rudebusch, G., and L.E.O. Svensson, 1999. "Policy Rules for Inflation Targeting," NBER Chapters, in: Monetary Policy Rules, pages 203-262, National Bureau of Economic Research.

[93] Sargent, T., and N. Wallace, 1975. "'Rational' Expectations, the Optimal Monetary Instrument, and the Optimal Money Supply Rule", Journal of Political Economy, 83 (2): 241254.

[94] Sargent, T.J., Williams, N., and T. Zha, 2006. "Shocks and Government Beliefs: The Rise and Fall of American Inflation," American Economic Review, 96(4), 1193-1224.

[95] Schmitt-Grohe', S., and M. Uribe, 2012, "What's News in Business Cycles?", forthcoming, Econometrica.

[96] Schorfheide, F., 2005. "Learning and Monetary Policy Shifts," Review of Economic Dynamics, vol. 8(2), pages 392-419.

[97] Sims, C.A., 2000. "Solving Linear Rational Expectations Models", Computational Economics, $20,1-20$.

[98] Slobodyan, S., and R. Wouters, 2012. "Learning in a Medium-Scale DSGE Model with Expectations Based on Small Forecasting Models," American Economic Journal: Macroeconomics, vol. 4(2), pages $65-101$.

[99] Smets, F., and R. Wouters, 2007. "Shocks and Frictions in US Business Cycles: A Bayesian DSGE Approach," American Economic Review, vol. 97(3), pages 586-606.

[100] Trabandt, M., 2007. "Sticky Information vs. Sticky Prices: a Horse Race in a DSGE Framework". Working Paper Series 209, Sveriges Riksbank.

[101] Treadwell, J., 2010. "Monetary Policy Indeterminacy Across the G7 and the Great Inflation", mimeo, UC Irvine.

[102] Uhlig, H., 1999. "A Toolkit for Analysing Nonlinear Dynamic Stochastic Models Easily," in R. Marimon and A. Scott: Computational Methods for the Study of Dynamic Economies. Oxford and New York: Oxford University Press, pp. 30-61.

[103] Williams, N., 2004. "Adaptive Learning and Business Cycles", mimeo, University of Wisconsin. 
[104] Woodford, M., 2010. "Robustly Optimal Monetary Policy with Near-Rational Expectations," American Economic Review, vol. 100(1), pages 274-303, March.

[105] Woodford, M., 2011. A Response to John Kay. Institure for New Economic Thinking. 